\title{
Removal of a doubly impacted plastic stent: a new technique
}

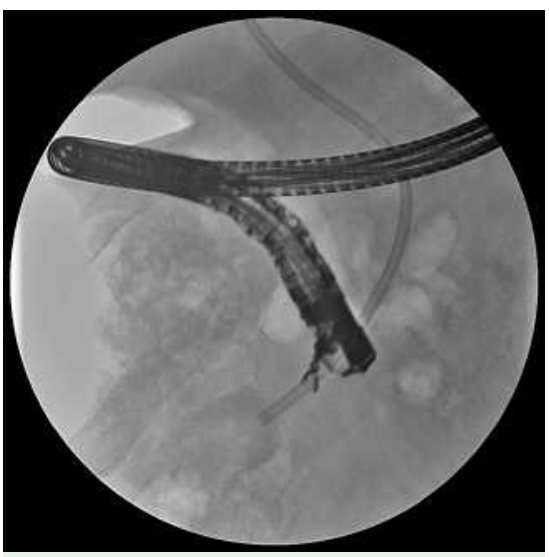

Fig. 1 The forceps marks out the extraluminal part of the stent.

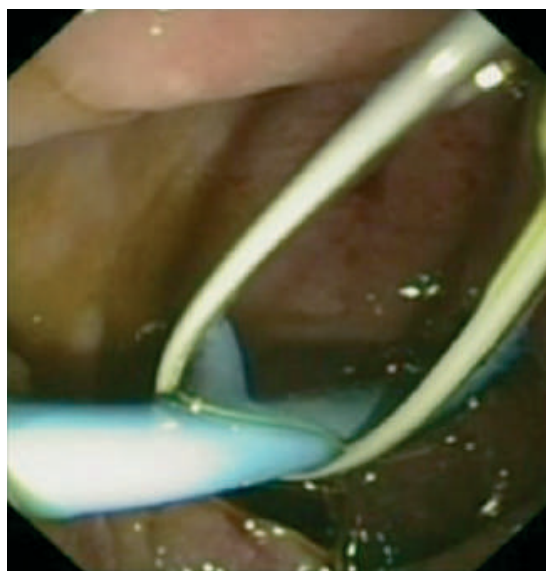

Fig. 2 "Road Runner" guide wire looping the stent.

Plastic stents are commonly used for various indications including drainage, stricture dilatation, and leakage. A complication is migration. The "Amsterdam" type stents have a slightly curved shaft and flaps near each end to prevent proximal or distal migration [1]. Despite the presence of flaps, proximal migration into the bile ducts or distal migration into the duodenum with subsequent passage per rectum are relatively frequent, but impaction and perforation of the bowel are rare [2].

In our department, we observed a 75 year-old Caucasian male with severe comorbidity admitted for obstructive jaundice and cholangitis secondary to multiple large common bile duct stones. Previous treatment was placement of a $12 \mathrm{~cm} 10 \mathrm{Fr}$ plastic biliary stent for incomplete stone

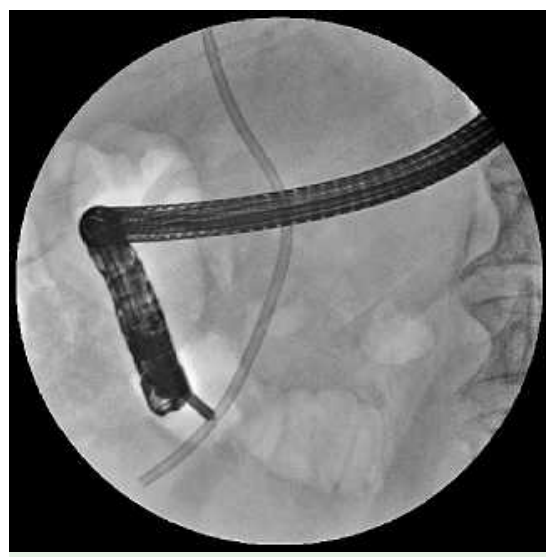

Fig. 3 Radiography shows the stent being grasped using the guide wire and metal cable.

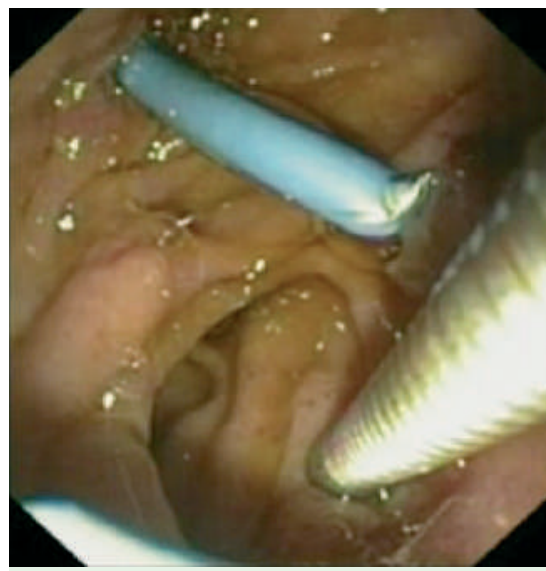

Fig. 4 End result after trimming the stent.

extraction. At endoscopic retrograde cholangiopancreatography, the distal end of the stent was found to have penetrated into the duodenal wall ( $\bullet$ Fig. 1, 2). The patient had no symptoms of perforation and no retroperitoneal air was observed at fluoroscopy. The retrieval maneuver was difficult because the proximal end of the stent was impacted into the common bile duct and the distal flap of the stent was impacted at the external surface of the duodenal wall. We introduced a 0.018-inch nitinol guide wire (Roadrunner ${ }^{\circledR}$, Cook Medical Inc., Bloomington, Indiana, USA) into the lumen of the duodenum. The distal end of the guide wire was grasped using a foreign body forceps and looped around the plastic stent before being retrieved outside the scope ( $\bullet$ Fig. 3). Both ends of the guide wire were locked into a mechanical lithotripsy

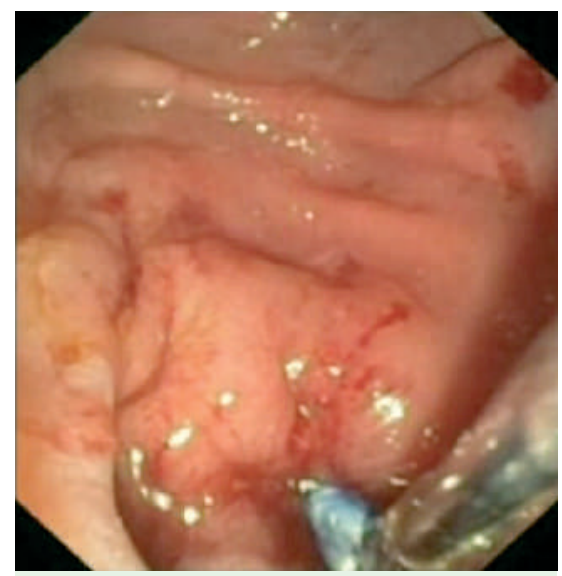

Fig. 5 The distal part of the stent, which had impacted into the duodenal wall, was retrieved using forceps after positioning the scope in front of the perforation.

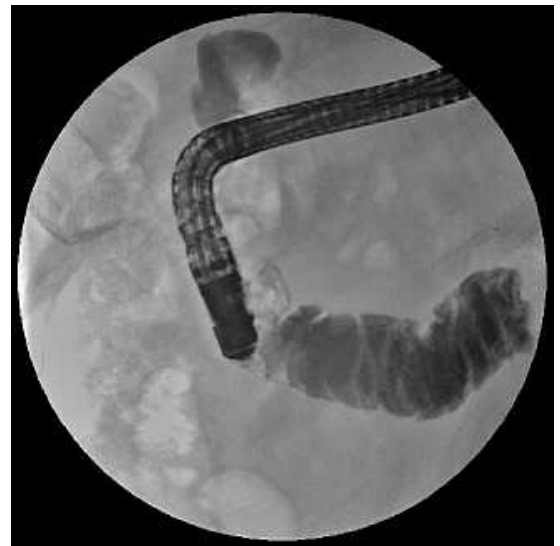

Fig. 6 Radiograph following the procedure: there is no evidence of leakage.

device and spun until the stent was cut through [3] ( $\bullet$ Fig. 4). The distal part of the stent, which had impacted into the duodenal wall, was retrieved using forceps after positioning the scope in front of the perforation ( $\mathbf{F i g . 5}$ ). To prevent the stretching of the duodenal wall, it was maintained fixed against the scope while the stent segment was retrieved into the operative channel. No peri- or postprocedural complications occurred ( $\bullet$ Fig. 6 ).

Endoscopy_UCTN_Code_TTT_1AR_2AZ 
M. Mutignani ${ }^{1}$, R. Salerno ${ }^{2}$, V. Perri ${ }^{1}$, A. Tringali ${ }^{1}$, G. Costamagna ${ }^{1}$

1 Digestive Endoscopy Unit, University Hospital A. Gemelli, Catholic University, Rome, Italy

2 Department of Medicine - Gastroenterology, Second University of Naples, Naples, Italy

\section{References}

1 Chaurasia O, Rauws E, Fockens $P$ et al. Endoscopic Techniques For Retrieval Of Proximally Migrated Biliary Stents. Gastrointest Endosc 1999; 50: 780-785

2 Esterl RM Jr, St Laurent M, Bay MK et al. Endoscopic biliary stent migration with small bowel perforation in a liver transplant recipient. J Clin Gastroenterol. 1997; 24: 106 110

3 Mutignani M, Dokas S, Perri V et al. Post-insertion tailoring of plastic biliary stents. Endoscopy 2006; 38: 856
Bibliography

DOI $10.1055 / \mathrm{s}-2008-1077407$

Endoscopy 2008; 40: E215-E216

(c) Georg Thieme Verlag KG Stuttgart · New York . ISSN 0013-726X

Corresponding author

\section{Mutignani, MD}

Digestive Endoscopy Unit

University Hospital A. Gemelli

Largo A. Gemelli 8

00168 Rome

Italy

Fax: +39-06-30156581

massimiliano.mutignani@rm.unicatt.it 